\title{
PATHOLOGICAL EXTENSION OF PROSTATE CANCER AS DEFINED BY GLEASON SCORE ON BIOPSY
}

\author{
MARCOS F. DALL'OGLIO, ALEXANDRE CRIPPA, MARIO PARANHOS, LUCIANO J. \\ NESRALLAH, KATIA R. LEITE, MIGUEL SROUGI \\ Division of Urology, Paulista School of Medicine, Federal University of Sao Paulo, UNIFESP, Sao Paulo, \\ SP, Brazil
}

\begin{abstract}
Introduction: Based on the importance of the Gleason score on the behavior of prostate adenocarcinoma, this study attempts to predict the extension of prostate adenocarcinoma pre-operatively, as defined by the Gleason score on biopsy, in individuals who will undergo radical prostatectomy.

Materials and Methods: We selected 899 individuals who underwent retropubic radical prostatectomy from 1988 to 2004. Clinical and pathological data obtained in the preoperative period were retrospectively analyzed through digital rectal examinations of the prostate, initial serum PSA levels and pathological data provided by biopsy. The Gleason score on biopsy was assessed and divided into 3 groups: 2 to 6,7 , and 8 to 10 , and correlated with the possibility of the disease being confined to the prostate.

Results: From the 899 selected patients, 654 (74\%) showed Gleason scores of 2 to 6,165 (18\%) had a score of 7 and 80 (9\%) had scores of 8 to 10 on biopsy. The likelihood of confined diseases, extraprostatic extensions, invasion of seminal vesicles and lymph nodal involvement were respectively: $74 \%, 18 \%, 8 \%$ and $0.8 \%$ for a Gleason score of 2 to $6,47 \%, 30 \%, 19 \%$ and $4 \%$ for a Gleason score of 7, and 49\%,29\%,18\% and 4\% for a Gleason score of 8 to 10 .

Conclusion: In patients who will undergo radical prostatectomy due to prostate adenocarcinoma, a Gleason score of 7 on biopsy shows the same behavior as a Gleason score of 8 to 10 in relation to extension of disease.
\end{abstract}

Key words: prostatic neoplasms; neoplasm staging; biopsy; needle; pathology

Int Braz J Urol. 2005; 31: 326-30

\section{INTRODUCTION}

The risk for progression of prostate cancer following radical prostatectomy (RP) is predicted by Gleason score, and pathological and surgical margins (1). The histological grade is regarded as a highly relevant prognostic factor $(2,3)$, and in tumors with high Gleason score, the disease is often associated with aggressive biological behavior and risk of occult disease
$(4,5)$. Attempting to determine the extension of the disease preoperatively is fundamental, since even tumors with a high Gleason score, but in a confined disease, present a disease-free outcome in $60 \%$ to $71 \%$ of cases (6). It is known that the recurrence of prostate cancer is higher in individuals with Gleason scores of 8 to 10 than with a score of 7 , as defined by the surgical specimen. In such cases, the disease is confined in $43.1 \%$ and $9.2 \%$ for Gleason 7 and 8-10 respectively (7). 
Preoperative prediction of the extension of the disease, which is determined by simply discriminating the Gleason score in the histopathology of biopsy fragments, will allow us to anticipate the possibility of extraprostatic disease in patients who will undergo RP.

Since there are no accurate data establishing if the Gleason score on biopsy could predict the location of prostate cancer (confined versus extraprostatic), this study aimed to compare prostate tumors with Gleason scores of 2 to 6,7 and 8 to 10 as defined by biopsy, and to verify the presence of extraprostatic disease following radical prostatectomy through the pathological parameters of the surgical specimen.

\section{MATERIALS AND METHODS}

We retrospectively studied 961 patients undergoing retropubic radical prostatectomy with bilateral selective iliac lymphadenectomy due to prostate adenocarcinoma, in the period from September 1988 to December 2002. The patient age range was from 40 to 83 years, with a mean age of $62.9 \pm 7.4$ years.

The study included patients whose medical records indicated the total number of fragments removed on biopsy, the number of fragments with cancer, Gleason score, PSA and pathological study of the surgical specimen. Fifty-four patients who received neoadjuvant treatment were excluded, as were another 8 who were diagnosed through endoscopic resection of the prostate or transvesical prostatectomy, thus totaling 899 patients. The mean PSA was $10.1 \pm$ $7.7 \mathrm{ng} / \mathrm{mL}$ (ranging from 0.3 to $72 \mathrm{ng} / \mathrm{mL}$ ). In relation to clinical stage, $432(48 \%)$ patients were classified as T1c, $219(24 \%)$ as T2a, $173(19.3 \%)$ as T2b, $68(7.6 \%)$ as T2c and $7(0.8 \%)$ as T3a. The mean percentage of affected fragments was $41 \% \pm 24 \%$ (ranging from 5\% to 100\%). The mean Gleason score on biopsy was $5.8 \pm 1.3$.

\section{Pathological Assessment}

All surgical specimens, consisting of prostate, seminal vesicles and obturator lymph nodes, were assessed by the same pathologist. Specimens were fixed in 10\% formalin for 6 hours in average and un- derwent a routine of measuring and weighing the gland on a digital balance with 2 decimal places of precision. Thin transversal sections were performed in the surgical margins relative to the bladder neck and the prostate apex. Using the urethra as a reference, the remaining gland had its margins stained with India ink, and was then sequentially sliced each 0.3 millimeters. Eight to 10 sections from each lobe were included for histological study. Seminal vesicles were sectioned at their base, and longitudinal sections were subsequently made for histological examination. Obturator lymph nodes were dissected and sliced for inclusion in the study.

The material underwent the usual processing in preparation for microscopic examination, with dehydration in alcohol, clearing in xylol and embedding in paraffin. Fragments were stained with hematoxylin and eosin and then analyzed under a binocular light microscope. The assessed parameters were:

Histological grade and Gleason score - The Gleason histological classification was used for assessing tumor differentiation, considering exclusively the acinar pattern.

Surgical margins - Positive margins were defined as the presence of a tumor in the surgical transection margins, as defined by the presence of India ink.

Infiltration of periprostatic tissue - Invasion of fat tissue and periprostatic neurovascular plexus was considered as non-confined disease.

Infiltration of seminal vesicles - Involvement of seminal vesicles was considered only when the tumor invaded their parenchyma, and not the adventitial area.

Lymph nodal metastases - Obturator lymph nodes containing tumor are considered as positive metastases.

Statistical analysis was performed with the qui-square test with values of $p<0.05$ being defined as significant.

\section{RESULTS}

Table-1 summarizes the pathological data for the Gleason score on biopsy and the location of prostate adenocarcinoma. Of the 899 selected patients, 
Table 1 - Gleason score on biopsy and location of prostate cancer in the surgical specimen.

\begin{tabular}{|c|c|c|c|c|c|}
\hline $\begin{array}{l}\text { Gleason Score } \\
\text { on Biopsy }\end{array}$ & Patients & Organ-confined & Extraprostatic & $\begin{array}{c}\text { Positive Seminal } \\
\text { Vesicle }\end{array}$ & $\begin{array}{c}\text { Positive Lymph } \\
\text { Nodes }\end{array}$ \\
\hline 2 to 6 & $654(73 \%)$ & $484(74 \%)$ & $118(18 \%)$ & $50 \quad(8 \%)$ & $2(<1 \%)$ \\
\hline 7 & 165 (18\%) & $78(47 \%)$ & $50(30 \%)$ & $31(19 \%)$ & $(4 \%)$ \\
\hline 8 to 10 & $80 \quad(9 \%)$ & $39(49 \%)$ & $23(29 \%)$ & $15(19 \%)$ & $(3 \%)$ \\
\hline Total & $899(100 \%)$ & $601(67 \%)$ & $191(21 \%)$ & $96(11 \%)$ & $(1 \%)$ \\
\hline
\end{tabular}

2 to 6 vs. 7 or 8 to $10(p<0.05) ; 7$ vs. 8 to $10(p>0.05)$

we observed that $654(73 \%)$ had a Gleason score of 2 to 6 . Another $165(18 \%)$ presented a Gleason score of 7 , and $80(9 \%)$ had a Gleason score of 8 to 10 , as identified by biopsy. Among the patients with a Gleason score of 7, 78 (47\%) had organ-confined location, $50(30 \%)$ presented extraprostatic invasion, $31(19 \%)$ had involvement of seminal vesicle and 6 (4\%) showed lymph nodal involvement. Those tumors with a Gleason score of 8 to 10 presented prostateconfined disease in $39(49 \%)$ of patients, 23 of them (29\%) had extraprostatic disease and $3(3 \%)$ showed lymph nodes affected by the disease.

There was a significant difference only when comparing Gleason scores of 2 to 6 with a 7 or an 8 to 10 , with no significant difference observed between the latter 2 groups.

\section{COMMENTS}

Our study showed that in individuals undergoing prostate biopsy, the presence of Gleason pattern 4 or 5 determines a risk of 51 to $53 \%$ for extraprostatic disease in the surgical specimen.

Merely dividing the Gleason score into ranges of 2 to 6 and 7 to 10 seems reasonable for predicting the extension of disease, since in univariate analysis the behavior of a Gleason score 7 was statistically identical to the behavior of patients with Gleason scores of 8 to 10 . In our opinion, the similarity in findings of extraprostatic disease between 7 and 8 to 10 can be explained by the presence of a pattern of 4 or 5 (8), which is invariably present. Patients with up to $10 \%$ of pattern 4 or 5 in the surgical specimen have more than a $70 \%$ probability of becoming diseasefree, while individuals with more than $50 \%$ of pat- tern 4 or 5 present progressive disease in $82 \%$ of cases (9).

The percentage of positive fragments on biopsy correlates to tumor volume. Additionally, the presence of a 4 or 5 pattern in the surgical specimen also determines a worse prognosis concerning outcome (10), however, as we have demonstrated, the chance of identifying confined disease is the same for 7 and for 8 to 10. Moreover, we could observe that patients with a Gleason score lower than 7 present a recurrence of the disease in $13 \%$ of cases, and this rate approaches $60 \%$ with a Gleason score between 7 and 10 (11). In our sample, we showed that $49 \%$ of individuals with a Gleason score between 8 and 10 had confined disease, $19 \%$ had neoplastic involvement of the seminal vesicles, and in only $8 \%$ of patients with a score lower than or equal to 6 were the seminal vesicles affected by the tumor. There is some controversy as whether a Gleason score of 7 has a different outcome from a score of 8 to 10 in relation to confined disease and recurrence (5). As we know, the Gleason score is composed of the 2 volumetrically prevalent patterns in the specimen, thus a Gleason score of 7 can be $3+4$ or $4+3$. Since the percentage of pattern 4 influences whether the disease is confined or not (10), studies comparing Gleason scores of 7, $4+3$ and $3+4$ have been published. Chan et al. (12) observed $34.7 \%$ of confined disease in patients undergoing radical prostatectomy with a Gleason score of 7 in the surgical specimen. However, the risk of progression was $20 \%$ higher with scores of $4+3$ than in the $3+4$ group after a 10 -year follow-up. However, in order to obtain the results, many of these studies derived from the surgical specimen and not from the biopsy (5), which may not be 
equal if we calculate the difference between Gleason scores of $3+4$ and $4+3$ from the biopsy fragments. A study conducted by Grober et al. (13) demonstrated that there was no difference between the 2 groups ( 3 +4 and $4+3$ ) of Gleason score 7 on biopsy in terms of the disease being confined or not, having extraprostatic extension or showing involvement of the seminal vesicles, which agrees with our data. In fact, a score 7 on biopsy should take into account not only the first score pattern, but PSA levels and the number of positive fragments on biopsy as well (14); if we have $4+3$ with 2 or less fragments affected by tumor in $68.7 \%$ of patients, the disease will be confined. On the other hand, if the score is $3+4$ with more than 2 affected fragments, this number will drop to $41.1 \%$. These data have been confirmed by Peller et al. (15) who, when comparing patients with Gleason scores of 7 and $100 \%$ positive fragments on biopsy with a Gleason score of 8 and the same number of positive fragments, were able to show agreement in $97 \%$ of cases for predicting confined disease.

When comparing our results with Tefilli et al. (7), we verified that when the Gleason score is between 2 and $6,74 \%$ of the patients have confined disease versus $69 \%$ with non-confined disease. On the other hand, with a score of 7 , we see $47 \%$ versus $43 \%$; that is, quite similar values. However, when comparing patients with a Gleason score between 8 and 10 , we found $48.8 \%$ of patients with confined disease versus only $9.2 \%$ with non-confined disease. This difference can be explained by the fact that the mean PSA in patients with a score of 7 was $12 \mathrm{ng} / \mathrm{mL}$ versus $25 \mathrm{ng} / \mathrm{mL}$ in patients with a Gleason score between 8 to 10 (7). Epstein et al. (1) found a rate of confined disease of $30 \%$ in men with a Gleason score of 7 , and, of them, approximately $70 \%$ were diseasefree after 10 years.

In relation to a Gleason score $\geq 8$, we found $9.5 \%$ to $31 \%$ of patients with confined disease (7). It is relevant that these patients had localized disease, because $82 \%$ of these individuals are not likely to have recurrent disease during a 5-year follow-up, despite the high Gleason score (16). Egan \& Bostwick (17) demonstrated that individuals with a Gleason score of 7 had confined disease in $48 \%$ of cases versus $53 \%$ in men with a Gleason score of 8 . In our study, we found $48.8 \%$ of confined disease with a score between 8 and 10. As shown previously, there is a wide variation in results when we attempt to use isolated parameters for predicting confined disease, and this is due to several factors that are involved in prostate adenocarcinoma. Since the construction of the first nomogram for predicting confined disease using PSA, clinical stage and Gleason score, more than one parameter is used in order to reduce the probability of error (3).

\section{CONCLUSION}

It is important to consider the presence of Gleason grade 4 or 5 on prostate biopsy for planning the management of prostate cancer. In these cases, the disease is organ-confined in the pathological examination of the surgical specimen in only half the cases.

\section{Adriana Sanudo performed the statistical analysis.}

\section{REFERENCES}

1. Epstein JI, Pound CR, Partin AW, Walsh PC. Disease progression following radical prostatectomy in men with Gleason score 7 tumor. J Urol 1998; 160:97-100; discussion 101.

2. Lerner SE, Blute ML, Bergstralh EJ, Bostwick DG, Eickholt JT, Zincke H: Analysis of risk factors for progression in patients with pathologically confined prostate cancers after radical retropubic prostatectomy. J Urol 1996; 156: 137-43.

3. Partin AW, Yoo J, Carter HB, Pearson JD, Chan DW, Epstein JI, Walsh PC. The use of prostate specific antigen, clinical stage and Gleason score to predict pathological stage in men with localized prostate cancer. J Urol 1993; 150: 110-4.

4. Lau WK, Bergstralh EJ, Blute ML, Slezak JM, Zincke H: Radical prostatectomy for pathological Gleason 8 or greater prostate cancer: influence of concomitant pathological variables. J Urol 2002; 167: 117-22. Erratum in: J Urol. 2004; 171: 811. 
5. Herman CM, Kattan MW, Ohori M, Scardino PT, Wheeler TM: Primary Gleason pattern as a predictor of disease progression in Gleason score 7 prostate cancer: a multivariate analysis of 823 men treated with radical prostatectomy. Am J Surg Pathol 2001; 25: 65760.

6. Tefilli MV, Gheiler EL, Tiguert R, Banerjee M, Sakr W, Grignon D, Wood DP Jr, Pontes JE: Role of radical prostatectomy in patients with prostate cancer of high Gleason score. Prostate 1999; 39: 60-6.

7. Tefilli MV, Gheiler EL, Tiguert R, Sakr W, Grignon DJ, Banerjee M, Pontes JE, Wood DP Jr: Should Gleason score 7 prostate cancer be considered a unique grade category? Urology 1999; 53:372-7.

8. Pan CC, Potter SR, Partin AW, Epstein JI: The prognostic significance of tertiary Gleason patterns of higher grade in radical prostatectomy specimens: a proposal to modify the Gleason grading system. Am J Surg Pathol. 2000; 24:563-9.

9. Stamey TA, McNeal JE, Yemoto CM, Sigal BM, Johnstone IM: Biological determinants of cancer progression in men with prostate cancer. JAMA 1999; 281: 1395-400.

10. Rubin MA, Mucci NR, Manley S, Sanda M, Cushenberry E, Strawderman M, et al.: Predictors of Gleason pattern 4/5 prostate cancer on prostatectomy specimens: can high grade tumor be predicted preoperatively? J Urol 2001; 165: 114-8.

11. Sakr WA, Tefilli MV, Grignon DJ, Banerjee M, Dey J, Gheiler EL, et al.: Gleason score 7 prostate cancer: a heterogeneous entity? Correlation with pathologic parameters and disease-free survival. Urology. 2000; 56: 730-4.

12. Chan TY, Partin AW, Walsh PC, Epstein JI: Prognostic significance of Gleason score $3+4$ versus Gleason score $4+3$ tumor at radical prostatectomy. Urology. 2000; 56: 823-7.

13. Grober ED, Tsihlias J, Jewett MA, Sweet JM, Evans AJ, Trachtenberg J, et al.: Correlation of the primary Gleason pattern on prostate needle biopsy with clinicopathological factors in Gleason 7 tumors. Can J Urol. 2004; 11: 2157-62.

14. Makarov DV, Sanderson H, Partin AW, Epstein JI. Gleason score 7 prostate cancer on needle biopsy: is the prognostic difference in Gleason scores $4+3$ and $3+4$ independent of the number of involved cores? J Urol. 2002; 167: 2440-2.

15. Peller PA, Young DC, Marmaduke DP, Marsh WL, Badalament RA: Sextant prostate biopsies. A histopathologic correlation with radical prostatectomy specimens. Cancer 1995; 75:530-8.

16. Mian BM, Troncoso P, Okihara K, Bhadkamkar V, Johnston D, Reyes AO, et al.: Outcome of patients with Gleason score 8 or higher prostate cancer following radical prostatectomy alone. J Urol. 2002; 167: 1675-80.

17. Egan AJ, Bostwick DG. Prediction of extraprostatic extension of prostate cancer based on needle biopsy findings: perineural invasion lacks significance on multivariate analysis. Am J Surg Pathol. 1997; 21:1496-500.
Received: February 1, 2005 Accepted after revision: May 5, 2005

\author{
Correspondence address: \\ Dr. Marcos F. Dall'Oglio \\ Rua Barata Ribeiro, no. 398, 5o. Andar \\ Sao Paulo, SP, 01308 - 000, Brazil \\ Fax: + $55113159-3618$ \\ E-mail: marcosdallogliouro@terra.com.br
}

